\title{
Anaerobic co-digestion of sodium hydroxide pretreated sugarcane leaves with pig manure and dairy manure
}

\author{
Juan Luo ${ }^{1,2}$, Haibo Meng ${ }^{2}$, Zonglu Yao ${ }^{2}$, Akiber Chufo Wachemo ${ }^{1,3}$, Hairong Yuan ${ }^{1}$, \\ Liang Zhang ${ }^{1}$, Xiujin $\mathrm{Li}^{\mathrm{i}^{*}}$ \\ (1. College of Chemical Engineering, Beijing University of Chemical Technology, Beijing 100029, China; 2. Chinese Academy of \\ Agricultural Engineering, Key Laboratory of Energy Resource Utilization from Agricultural Residues, Beijing 100125, China; \\ 3. Department of Water Supply and Environmental Engineering, Arba Minch University, Arba Minch, Ethiopia)
}

\begin{abstract}
Sugarcane leaves (SL) pretreated by alkali was used as substrate to enhance biogas production via mesophilic anaerobic digestion (AD) in this study. Effectiveness of different concentrations of $\mathrm{NaOH}$ pretreatment on AD performance was investigated. Results showed that compared to untreated sample of SL, the lignocellulose (LCH) content of $\mathrm{NaOH}$ pretreated group was decreased by $5.79 \%-16.85 \%$. However, the cumulative biogas production of the pretreated samples increased in the range of $34.54 \%-82.67 \%$; moreover, T90 was shorten by $5-7 \mathrm{~d}$. The highest anaerobic digestibility of SL was achieved at $6 \% \mathrm{NaOH}$ pretreatment, which produced $287.30 \mathrm{~mL} / \mathrm{g}$ TS of biogas. A significant interactive effect of the three parameters (temperature, $\mathrm{SL} /$ manure mixing ratio and $\mathrm{C} / \mathrm{N}$ ratio) was found on the biogasification of anaerobic co-digestion, and a maximum biogas production was achieved at $36.2^{\circ} \mathrm{C}$, mixing ratio of 1.6 and $\mathrm{C} / \mathrm{N}$ ratio of 29.2 . These show that the verification experiment confirmed the optimization results. This study provides meaningful insight for exploring efficient pretreatment strategy and optimal condition to stabilize and enhance AD performance for practical application.
\end{abstract}

Keywords: $\mathrm{NaOH}$ pretreatment, co-digestion, sugarcane leaves, pig manure, dairy manure

DOI: $10.25165 /$ j.ijabe.20181104.4079

Citation: Luo J, Meng H B, Yao Z L, Wachemo A C, Yuan H R, Zhang L, et al. Anaerobic co-digestion of sodium hydroxide pretreated sugarcane leaves with pig manure and dairy manure. Int J Agric \& Biol Eng, 2018; 11(4): 224-229.

\section{Introduction}

Sugarcane is one of the main sugar crops cultivated in China, accounts more than $85 \%$ of perennial planting area for sugar crops. The yield of sugarcane in China is over 116.97 million $t$ in 2015 (National Bureau of Statistics of China, 2016), producing huge amount of SL as agricultural byproduct, which is believed to be rich in organic matter. However, more than $80 \%$ of the SL production remains unused and causes serious environmental and safety problems due to burning operations in open air. Meanwhile, China is also commonly known in major animal husbandry. According to the pilot programs to promote the utilization of agricultural waste resource, the annual yield of livestock and poultry manure production were over 3.8 billion tons ${ }^{[1]}$, but the comprehensive utilization rate is less than $60 \%$ in 2016 . That means at least 1.52 billion tons of animal manure has not been used effectively, which could cause serious environmental pollution ${ }^{[2]}$.

Anaerobic digestion (AD) has been widely employed as an

Received date: $2017-12-30 \quad$ Accepted date: $2018-06-28$

Biographies: Juan Luo, PhD candidate, research interests: biomass waste anaerobic digestion, Email: emimi2008@126.com; Haibo Meng, PhD, Researcher, research interests: biological and agricultural engineering, Email: newmhb7209@163.com; Zonglu Yao, PhD, Senior Engineer, research interests: biological and agricultural engineering, Email: yaozonglu@163.com; Akiber Chufo Wachemo, $\mathrm{PhD}$, research interests: biomass waste anaerobic digestion, Email: akiberchufo@yahoo.com; Hairong Yuan, PhD, research interests: biomass waste anaerobic digestion, Email: yuanhairong75@163.com; Liang Zhang, PhD candidate, research interests: biomass waste anaerobic digestion, Email: 13810923833@126.com.

*Corresponding author: Xiujin Li, PhD, Professor, research interests: biomass waste anaerobic digestion. No.15 Beisanhuan East Road, Chaoyang District, Beijing 100029, China. Tel/Fax.: +86-10-6443-2281, Email: xjli@, mail.buct.edu.cn. efficient method of treating organic wastes ${ }^{[2,3]}$, which is an ideal way for comprehensive utilization of SL. Different organic materials can be degraded by microorganisms in anaerobic conditions during $\mathrm{AD}$, product energy-rich biogas that can be used for production of vehicle fuel, electric power and heat ${ }^{[4]}$. Nevertheless, the intricate composition of lignocellulosic material, consisting of three main types of polymers (cellulose, hemicellulose and lignin), often restricts the biodegradability and consequently results in low bio-digestion efficiency and methane production $^{[5]}$. Anaerobic co-digestion technology provides simultaneous digestion of different organic wastes, and can be an interesting strategy to avoid nutritional deficiency and imbalance ${ }^{[6,7]}$. This technology achieves more appropriate carbon to nitrogen ratio $(\mathrm{C} / \mathrm{N})$ by co-digesting different nutrient-rich wastes ${ }^{[8]}$, which improves biodegradability and increases the biogas yield. There have been many studies on the co-digestion of crop straw and animal manure which explored the benefits of substrates synergy. Ye et al. ${ }^{[9]}$ carried out experiments on the co-digestion of rice straw, kitchen waste and pig manure. Zhang et al. ${ }^{[10]}$ conducted the anaerobic co-digestion of goat manure with wheat straw, corn straw, and rice straw. Mei et al. ${ }^{[11]}$ optimized the co-digestion parameters of rice straw and chicken manure. In all these studies, the anaerobic co-digestion of crop straw with different kinds of manure has significantly improved the production of biogas.

Due to high $\mathrm{C} / \mathrm{N}$ ratio, a large amount of lignocellulosic materials and waxy layer covered surface are less available for microorganisms ${ }^{[12]}$. As result, crop straws including SL are difficult to be biodegraded and need much more hydraulic retention time ${ }^{[13,14]}$. Pretreatment prior to AD has been proven to be one of simple and effective methods to improve biodegradability of lignocellulosic materials. $\mathrm{Zhu}$ et al. $^{[15]}$ found that lignin 
degradation during pretreatment increased from $9.1 \%$ to $46.2 \%$ when the concentration of $\mathrm{NaOH}$ increased from $1.0 \%$ to $7.5 \%$. Sambusiti et al. ${ }^{[16]}$ considered that $\mathrm{NaOH}$ pretreatment could promote hydrolysis of lignocelluloses and increased methane production by $47 \%$.

In this study, the effects of $\mathrm{NaOH}$ pretreatment on anaerobic digestibility of SL were investigated. Based on this, AD experiments were carried out with mixture of pretreated SL, pig manure (PM) and dairy manure (DM). To optimize the AD process and improve the biogas production efficiency, a Box-Behnken experimental design (BBD) combined with response surface methodology (RSM) was applied to determine the effect of temperature, mixing ratio and $\mathrm{C} / \mathrm{N}$ ratio on the biogasification.

\section{Materials and methods}

\subsection{Raw materials and inoculum}

The SL sample was collected from Dianbai County of Maoming City (Guangdong province, China). After sample drying on open air, it was cut into the size of $10 \mathrm{~mm}$ with a hammer mill. The PM and DM were collected from Daxing District, Beijing and stored at $-20^{\circ} \mathrm{C}$ in a refrigerator until used for $\mathrm{AD}$ tests. The anaerobic sludge used as inoculum was collected from a $50 \mathrm{~L}$ mesophilic anaerobic digester in the laboratory of Chinese Academy of Agricultural Engineering (CAAE). The main chemical characteristics of raw materials and inoculum are presented in Table 1.

Table 1 Characteristics of raw materials and inoculum

\begin{tabular}{|c|c|c|c|c|c|c|c|c|}
\hline Substrate & $\mathrm{TS} / \%$ & $\mathrm{VS} / \%$ & $\mathrm{TN}^{\mathrm{a}} / \%$ & $\mathrm{TC}^{\mathrm{a}} / \%$ & Cellulose $\mathrm{e}^{\mathrm{a}} \%$ & Hemicellulose ${ }^{\mathrm{a}} / \%$ & Lignin $/ \%$ & $\mathrm{C} / \mathrm{N}$ \\
\hline SL & 87.54 & 80.25 & 0.64 & 43.13 & 36.11 & 30.02 & 9.66 & 67.39 \\
\hline PM & 24.18 & 17.02 & 1.33 & 17.41 & $\mathrm{ND}^{\mathrm{b}}$ & $\mathrm{ND}^{\mathrm{b}}$ & $\mathrm{ND}^{\mathrm{b}}$ & 13.09 \\
\hline $\mathrm{DM}$ & 27.22 & 20.16 & 2.44 & 28.92 & $\mathrm{ND}^{\mathrm{b}}$ & $\mathrm{ND}^{\mathrm{b}}$ & $\mathrm{ND}^{\mathrm{b}}$ & 18.78 \\
\hline Inoculum & 7.22 & 3.84 & 0.19 & 5.11 & $\mathrm{ND}^{\mathrm{b}}$ & $\mathrm{ND}^{\mathrm{b}}$ & $\mathrm{ND}^{\mathrm{b}}$ & 26.89 \\
\hline
\end{tabular}

Note: ${ }^{\text {a }}$ dry basis; ${ }^{\text {b }}$ not determined.

\subsection{Experimental design}

2.2.1 Anaerobic digestion of $\mathrm{NaOH}$ pretreated SL for Test 1

In this study, sodium hydroxide was used as the pretreatment agent. The SL was pretreated with $2 \%, 4 \%, 6 \%$ and $8 \% \mathrm{NaOH}$ (based on the dry weight of SL) at room temperature $\left(25^{\circ} \mathrm{C}\right)$ for 3 days, moisture content during pretreatment was adjusted to $30 \%$ based on the dry weight of SL. The anaerobic digester used in this study was $0.5 \mathrm{~L}$ AD bottle (working volume was about $0.4 \mathrm{~L}$ ) with $1 \mathrm{~L}$ gas collecting bottle and $1 \mathrm{~L}$ beaker for each setup. The organic loading of each digester was set at $65 \mathrm{~g} \mathrm{TS} / \mathrm{L}$. Experimental AD bottles were fed with mixture of pretreated SL and inoculum, and the control ones were fed with untreated SL and inoculum. SL and inoculum were added to the $\mathrm{AD}$ bottles at the mixture ratio of $1: 3(\mathrm{TS} / \mathrm{TS})$. All the $\mathrm{AD}$ tests were set-up at mesophilic temperature $(35 \pm 1)^{\circ} \mathrm{C}$ for 36 days. Three parallel experiments were set up for each group and the control group (inoculum only) was set. Results presented in this paper have deducted biogas production of inoculum.

\subsubsection{Parameter optimization (Test 2) of mixed materials}

Based on the Test 1 results of AD with $\mathrm{NaOH}$ pretreated SL, anaerobic co-digestion experiments of pretreated SL, PM and DM (DM and PM mixing ratio was 1:1) were carried out. According to previous studies, three levels of temperature $\left(30^{\circ} \mathrm{C}, 35^{\circ} \mathrm{C}, 40^{\circ} \mathrm{C}\right)$, mixing ratio $(1: 2,1: 1,2: 1)$ and $\mathrm{C} / \mathrm{N}$ ratio $(20: 1,25: 1,30: 1)$ were designed to evaluate their effect on the biogasification. The $\mathrm{C} / \mathrm{N}$ ratio of the substrate was adjusted using urea. In this study, the anaerobic fermentation lasted for $36 \mathrm{~d}$. BBDs are a class of rotatable or nearly rotatable second-order designs based on three-level incomplete factorial designs. Seventeen continuous-flow experiments were conducted based on the three levels of the temperature, mixing ratio and $\mathrm{C} / \mathrm{N}$ ratio. Each group was performed in triplicate.

Table 2 Coded and actual values of variables used in BBDs

\begin{tabular}{cccc}
\hline & \multicolumn{3}{c}{ Actual value } \\
\cline { 2 - 4 } Coded value & Temperature $/{ }^{\circ} \mathrm{C}$ & Mixing ratio & $\mathrm{C} / \mathrm{N}$ ratio \\
\hline-1 & 30 & $1: 2$ & $20: 1$ \\
0 & 35 & $1: 1$ & $25: 1$ \\
1 & 40 & $2: 1$ & $30: 1$ \\
\hline
\end{tabular}

\subsection{Analytical methods}

The TS, VS, and $\mathrm{pH}$ of the raw materials were determined using the standard water and wastewater testing methods [17] Total $\mathrm{C}$ and total $\mathrm{N}$ contents were determined by the elemental analyzer (EA2400 II, PerkinElmer, USA). The contents of cellulose, hemicellulose and lignin in the SL before and after pretreatment were measured by fiber analyzer (FT350, FOSS, Danmark). The daily biogas production for each anaerobic digester was recorded using the water displacement method and the corresponding cumulative biogas volume was also calculated. The methane content in the produced biogas was analyzed by Gas Chromatography (Model 7890A, Agilent, USA).

\subsection{Data analyses}

RSM was used to build the most fitted model and optimize the fermentation system using Design Expert version 7.0. One-way analysis of variance (ANOVA) was employed to study the primary effects of the selected parameters on biogas production. Differences were considered significant when the p-values were less than 0.05 .

\section{Results and discussion}

\subsection{Effects of $\mathrm{NaOH}$ pretreatment on $\mathrm{AD}$ of $\mathrm{SL}$}

\subsubsection{Changes in LCH of SL}

The main compositions of SL before and after different $\mathrm{NaOH}$ pretreatment are shown in Table 3. The cellulose and hemicelluloses of untreated SL accounted for $36.11 \%$ and $30.02 \%$, respectively and the content of the lignin was $9.66 \%$. The results show that a considerable amount of LCH appeared to be decomposed and converted to soluble components. The content of cellulose and hemicelluloses significantly decreased to $34.47 \%-30.54 \%$ and $27.57 \%-25.18 \%$ in $\mathrm{NaOH}$ pretreated samples, which was $4.54 \%-15.43 \%$ and $8.16 \%-16.12 \%$ lower than that of the untreated group. The content of lignin also decreased from $9.36 \%$ to $7.30 \%$, which suggests that $\mathrm{NaOH}$ pretreatment can partially remove lignin to enhance anaerobic biodegradation of SL. This might be due to the presence of $\mathrm{OH}^{-}$in $\mathrm{NaOH}$ which altered the structure of $\mathrm{LCH}^{[18-20]}$. As a result, anaerobic microbes could get better access to utilize more substrate and improve the performance of $\mathrm{AD}$. 
Table 3 Effects of pretreatment on the composition of SL $(\%, D M)^{c}$

\begin{tabular}{ccccc}
\hline Pretreatment & Cellulose & Hemicellulose & Lignin & $\begin{array}{c}\text { LCH } \\
\text { (Lignin, cellulose, } \\
\text { and hemicellulose) }\end{array}$ \\
\hline Untreated & $36.11 \pm 0.22$ & $30.02 \pm 0.32$ & $9.66 \pm 0.23$ & $75.79 \pm 0.34$ \\
$2 \% \mathrm{NaOH}$ & $34.47 \pm 0.48$ & $27.57 \pm 0.69$ & $9.36 \pm 0.10$ & $71.40 \pm 1.23$ \\
$4 \% \mathrm{NaOH}$ & $32.83 \pm 0.15$ & $25.64 \pm 0.13$ & $8.59 \pm 0.09$ & $67.06 \pm 0.12$ \\
$6 \% \mathrm{NaOH}$ & $30.97 \pm 0.46$ & $26.03 \pm 0.16$ & $7.66 \pm 0.07$ & $64.65 \pm 0.25$ \\
$8 \% \mathrm{NaOH}$ & $30.54 \pm 0.57$ & $25.18 \pm 0.18$ & $7.30 \pm 0.13$ & $63.02 \pm 0.27$ \\
\hline
\end{tabular}

Note: ${ }^{\mathrm{c}}$ Values are the means $\pm \mathrm{SD}(n=3) ; \mathrm{DM}=$ Dry matter.

\subsubsection{Biogas production}

The daily biogas production of $\mathrm{NaOH}$ pretreatment and untreated SL are shown in Figure 1a. Similar trends of daily biogas production were observed for different reactors during entire digestion time. More specifically, the daily biogas production showed initial increase up to peak point and then decreased, and all experiments reached the highest daily biogas production peak between day 8 and day 10 of the digestion time. The peak value of daily biogas production significantly fluctuated, possibly because of the different degree of degradation of complex organic matter. With the gradual degradation of degradable organics, the daily biogas production showed a downward trend and approached zero at day 36. The highest daily biogas peaks appeared for $\mathrm{NaOH}$ pretreated sample a little earlier than the untreated sample, which could be attributed to the availability of the readily soluble substances in substrate. The SL with $6 \% \mathrm{NaOH}$ pretreatment had comparatively highest daily biogas production $(386 \mathrm{~mL} / \mathrm{d})$, which was followed by $2 \% \mathrm{NaOH}$ pretreatment $(340 \mathrm{~mL} / \mathrm{d})$. On the other hand, the optimum daily biogas production of SL with $4 \%$, $8 \% \mathrm{NaOH}$ pretreatment and untreated were $330 \mathrm{~mL} / \mathrm{d}, 289 \mathrm{~mL} / \mathrm{d}$ and $251 \mathrm{~mL} / \mathrm{d}$.

The cumulative biogas production of SL with different $\mathrm{NaOH}$ pretreatments is shown in Figure 1b. $6 \% \mathrm{NaOH}$ treatment in all groups commands a significant premium, with the cumulative biogas production reached $4976.2 \mathrm{~mL}$ and unit dry mass biogas production reached $287.31 \mathrm{~mL} / \mathrm{g}$ TS. The cumulative biogas production of the control test was only $2725.4 \mathrm{~mL}$ (unit dry mass biogas production was $157.36 \mathrm{~mL} / \mathrm{g}$ TS ). The results showed that the anaerobic digestibility and conversion rate of SL were considerably improved after $\mathrm{NaOH}$ pretreatment. This indicated that alkali pretreatment could decompose cellulose and hemicellulose into relatively readily biodegradable components, and this pretreatment could break down the linkage between polysaccharide and lignin to make cellulose and hemicellulose more accessible to bacteria ${ }^{[21-24]}$.

\subsubsection{AD time}

The AD time required to convert the optimum amount of raw material reflects the efficiency of the process, and shortening of $\mathrm{AD}$ time can efficiently lower the cost of operation and enhance productivity. $\mathrm{T} 90^{[25]}$ digestion time is defined as the time required to produce $90 \%$ of the maximum biogas production. In this study, the time needed to produce $70 \%$ and $90 \%$ of maximum biogas production is shown in Table 4. Compared with the control test, T90 of $\mathrm{NaOH}$ pretreated SL was shortened by 5-7 d, while cumulative biogas production and unit dry mass biogas production increased significantly. This indicated that $\mathrm{NaOH}$ pretreatment had great potential to improve economic efficiency in reducing the digestion time.

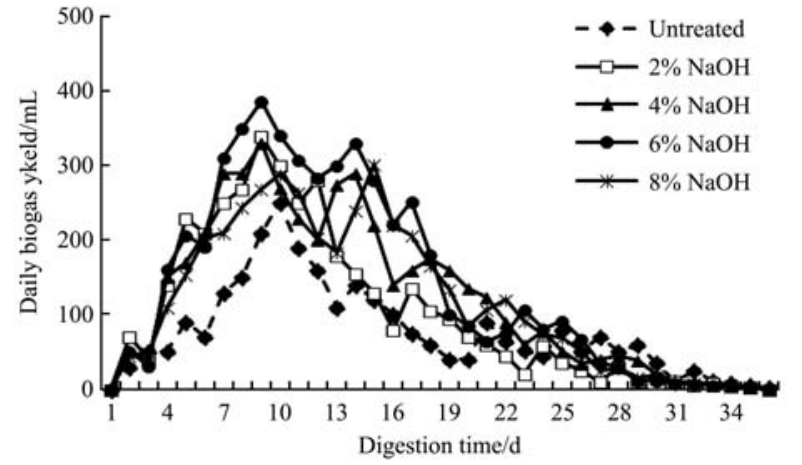

a

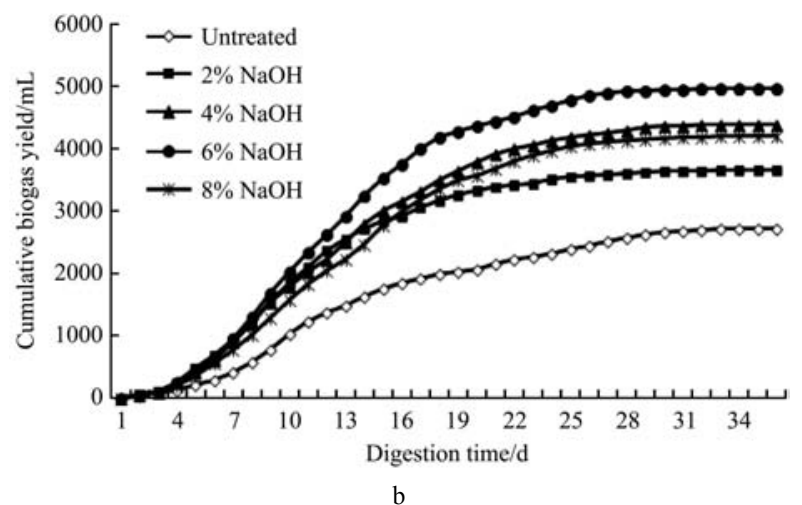

Figure 1 Daily biogas yield and cumulative biogas yield

Table 4 Effects of different pre-treatment on digestion period

\begin{tabular}{ccccc}
$\begin{array}{c}\text { Pretreatment } \\
\text { method }\end{array}$ & $\begin{array}{c}\text { Cumulative biogas } \\
\text { production/mL }\end{array}$ & $\begin{array}{c}\text { Unit dry mass biogas } \\
\text { production } / \mathrm{mL} \cdot \mathrm{g}^{-1} \mathrm{TS}\end{array}$ & T70 & T90 \\
\hline Untreated & 2725.4 & 157.36 & 17 & 27 \\
$2 \% \mathrm{NaOH}$ & 3665.7 & 211.65 & 14 & 20 \\
$4 \% \mathrm{NaOH}$ & 4394.8 & 253.74 & 15 & 22 \\
$6 \% \mathrm{NaOH}$ & 4976.2 & 287.31 & 15 & 22 \\
$8 \% \mathrm{NaOH}$ & 4208.5 & 242.98 & 16 & 22 \\
\hline
\end{tabular}

Note: T70 and T90 is the time needed to produce $70 \%$ and $90 \%$ of the maximum biogas production in $\mathrm{AD}$ respectively.

\subsubsection{Methane content}

The methane content in the biogas from SL with different pretreatment was maintained at $50 \%-60 \%$, which was significantly higher than that of the untreated (Figure 2). The methane content of $\mathrm{NaOH}$ pretreated SL reached the highest peak faster than that of the untreated one. There was no statistically significant difference in the maximum methane content between the four $\mathrm{NaOH}$ pretreated SL and SL with $8 \% \mathrm{NaOH}$ pretreatment had the highest

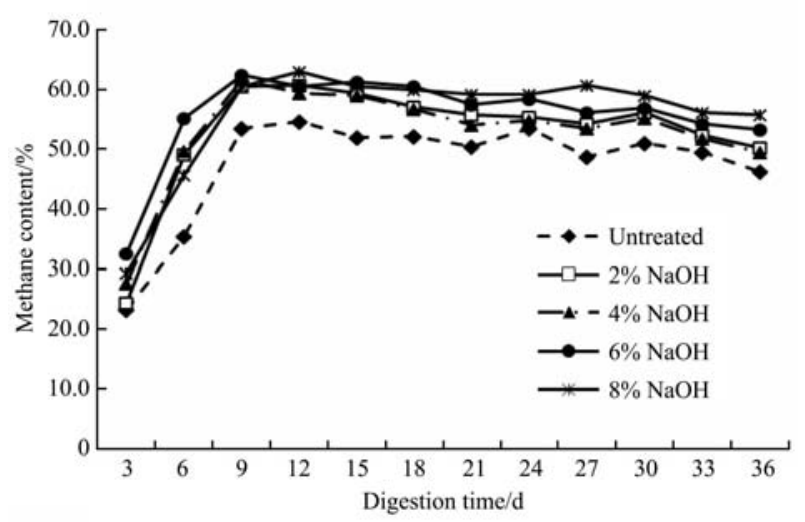

Figure 2 Variation of methane content at different $\mathrm{NaOH}$ concentration 
methane content of $63.1 \%$, which was much higher than that of the untreated test $(54.5 \%)$. This indicated that pretreatment could increase methane content to a certain extent, because pretreated SL could provide more soluble organic matter for microbial decomposition and utilization.

\subsection{Anaerobic co-digestion of $\mathrm{NaOH}$ pretreated SL with PM} and DM

\subsubsection{Modeling of AD for biogas production}

Based on the aforementioned analysis, $\mathrm{NaOH}$ pretreatment was shown to exhibit favorable effectiveness on the degradation of the structures of hemicelluloses in SL. BBD was used to investigate the effect of three variables: temperature, SL/manure mixing ratio and $\mathrm{C} / \mathrm{N}$ ratio on the biogasification of SL, DM and PM in 17 runs of the experiment. The biogas yield of each run was shown in Table 5. The results in Table 6 were used for ANOVA and multiple regression analysis in Design-Expert software using the polynomial model equation. This approach enabled prediction of the optimum degree of biogas production and its corresponding optimum variables $^{[26]}$. One-way ANOVA was employed to test and analyze models. The best-fit model was found as a quadratic model for the biogasification of mixed raw materials. The equation (built with codified factors) used to obtain the highest rate of biogas production was as follows:

FBiogas $=314.56+39.075 A+9.3 B+41.35 C+1.2 A B+16.8 A C+$

$$
32.05 B C-114.73 A^{2}-37.53 B^{2}-36.53 C^{2}
$$

where, $A$ is the temperature; $B$ is the mixing ratio; $C$ is the $C / \mathrm{N}$ ratio. The results of the ridge analysis revealed that the optimal conditions were $36.2^{\circ} \mathrm{C}$ (temperature), 1.6 (mixing ratio), and 29.2 $(\mathrm{C} / \mathrm{N}$ ratio), which results in a predicted biogas production of $346 \mathrm{~mL} / \mathrm{g}$ TS.

Table 5 Box-Behnken design for AD of mixing raw material

\begin{tabular}{|c|c|c|c|c|c|c|c|}
\hline \multirow[b]{2}{*}{ Number } & \multicolumn{3}{|c|}{ Coded } & \multicolumn{3}{|c|}{ Uncoded } & \multirow{2}{*}{$\begin{array}{c}\text { Response } \\
\text { Biogas } \\
\text { Production } \\
/ \mathrm{mL} \cdot(\mathrm{g} \cdot \mathrm{TS})^{-1}\end{array}$} \\
\hline & $\begin{array}{c}\text { Temperature } \\
{ }_{/}^{\circ} \mathrm{C}\end{array}$ & $\begin{array}{l}\text { Mixing } \\
\text { ratio }\end{array}$ & $\mathrm{C} / \mathrm{N}$ & $\begin{array}{c}\text { Temperature } \\
{ }^{\circ} \mathrm{C}\end{array}$ & $\begin{array}{l}\text { Mixing } \\
\text { ratio }\end{array}$ & $\mathrm{C} / \mathrm{N}$ & \\
\hline 1 & 1 & 0 & 1 & 40 & $1: 1$ & $30: 1$ & 258.5 \\
\hline 2 & -1 & 1 & 0 & 30 & $2: 1$ & $25: 1$ & 132.4 \\
\hline 3 & 0 & -1 & -1 & 35 & $1: 2$ & $20: 1$ & 215.3 \\
\hline 4 & -1 & -1 & 0 & 30 & $1: 2$ & $25: 1$ & 119.7 \\
\hline 5 & 0 & 0 & 0 & 35 & $1: 1$ & $25: 1$ & 326.8 \\
\hline 6 & 0 & -1 & 1 & 35 & $1: 2$ & $30: 1$ & 243.6 \\
\hline 7 & 0 & 1 & -1 & 35 & $2: 1$ & $20: 1$ & 173.3 \\
\hline 8 & 1 & 0 & -1 & 40 & $1: 1$ & $20: 1$ & 151.9 \\
\hline 9 & 0 & 0 & 0 & 35 & $1: 1$ & $25: 1$ & 325.1 \\
\hline 10 & 1 & -1 & 0 & 40 & $1: 2$ & $25: 1$ & 189.8 \\
\hline 11 & 0 & 0 & 0 & 35 & $1: 1$ & $25: 1$ & 308.3 \\
\hline 12 & 1 & 1 & 0 & 40 & $2: 1$ & $25: 1$ & 207.3 \\
\hline 13 & -1 & 0 & -1 & 30 & $1: 1$ & $20: 1$ & 101.7 \\
\hline 14 & -1 & 0 & 1 & 30 & $1: 1$ & $30: 1$ & 141.1 \\
\hline 15 & 0 & 1 & 1 & 35 & $2: 1$ & $30: 1$ & 329.8 \\
\hline 16 & 0 & 0 & 0 & 35 & $1: 1$ & $25: 1$ & 298.4 \\
\hline 17 & 0 & 0 & 0 & 35 & $1: 1$ & $25: 1$ & 314.2 \\
\hline
\end{tabular}

Analysis of variance is shown in Table 6. The results of the fitting degree and significance test of the regression equation revealed that the regression equation was significant. Moreover, the fitting result of the response was good, where the regression coefficient was high $\left(R^{2}=0.9920\right)$. The $F$-value of the model was
96.39 with a very low value of probability $(p<0.0001)$ (Table 6$)$, implying a highly significant effect on the biogas production process. Furthermore, the "lack of fit" has a $p$-value of 0.62 which showed no significance, implying a good fit of the model prediction.

Table 6 ANOVA for the response surface quadratic model

\begin{tabular}{cccccc}
\hline Source & Sum of squares & DF & MS & F-value & Prob $>F$ \\
\hline Model & 103838.81 & 9 & 11537.64 & 96.38 & $<0.0001$ \\
A-temperature & 12214.845 & 1 & 12214.84 & 102.04 & $<0.0001$ \\
B-Mixing ratio & 691.92 & 1 & 691.92 & 5.78 & 0.0472 \\
C-C/N & 13678.58 & 1 & 13678.58 & 114.27 & $<0.0001$ \\
AB & 5.76 & 1 & 5.76 & 0.048 & 0.8326 \\
AC & 1128.96 & 1 & 1128.96 & 9.43 & 0.0180 \\
BC & 4108.81 & 1 & 4108.81 & 34.32 & 0.0006 \\
A $^{2}$ & 55423.044 & 1 & 55423.04 & 463.01 & $<0.0001$ \\
B $^{2}$ & 5930.5301 & 1 & 5930.53 & 49.54 & 0.0002 \\
C $^{2}$ & 5618.6985 & 1 & 5618.70 & 46.94 & 0.0002 \\
Residual & 837.897 & 7 & 119.70 & & \\
Lack of Fit & 276.525 & 3 & 92.17 & 0.66 & 0.6199 \\
Pure Error & 561.372 & 4 & 140.34 & & \\
Total & 104676.7 & 16 & & & \\
\hline
\end{tabular}

3.2.2 Main effects and interactions between parameters

It can be seen from Table 6 that each item and interaction term $\mathrm{AC}$ and $\mathrm{BC}$ are significant $(p<0.05)$, implying that all of them have a significant impact on biogasification. The experimental results were given in three-dimensional response surface plots that show the simultaneous effect of two factors on biogas production obtained from Equation (1). Figure 3a depicts a three dimensional plot showing the effects of temperature and mixing ratio on the biogas production of mixed raw material. A large change in the biogas production was observed by changing each parameter indicated that both parameters and their interaction were effective. With the increase of temperature, the biogas production initially increased and then gradually decreased after reaching its optimized value. When the temperature was at $35.8^{\circ} \mathrm{C}$, the mixing ratio was 1.35 and $\mathrm{C} / \mathrm{N}$ fixed at 25 , the biogas production reached the maximum value.

Increasing the mixing ratio and $\mathrm{C} / \mathrm{N}$ ratio to the optimal values as determined by RSM resulted in increased biogas production. However, further increases in mixing ratio resulted in reduced biogas production (Figure $3 \mathrm{~b}$ ). The optimal mixing ratio and $\mathrm{C} / \mathrm{N}$ ratio was about 1.6 and 29 , respectively. A lower $\mathrm{C} / \mathrm{N}$ ratio causes ammonia accumulation which could make $\mathrm{pH}$ value exceed 8.5, create a condition that not favorable for methanogenic bacteria. In contrast, a high $\mathrm{C} / \mathrm{N}$ ratio is an indication of rapid consumption of nitrogen by methanogens, and results in lower gas production $^{[27]}$. Previous report showed a wide range of optimal $\mathrm{C} / \mathrm{N}$ ratios (10-90) in methane fermentation, but $\mathrm{C} / \mathrm{N}$ ratio within 25-30 being the most suitable region for AD process ${ }^{[28]}$, which was consistent with our results.

The combined effect of temperature and $\mathrm{C} / \mathrm{N}$ ratio on biogas production is shown in Figure 3c. Biogas production increases first and then decreases with continuous increase of temperature after reaching its optimal value, which showed a similar trend like results in Figure 3a. The maximum value of biogas production could be achieved when the temperature was at $36^{\circ} \mathrm{C}, \mathrm{C} / \mathrm{N}$ was at 28 and the mixing ratio fixed at 1.25 . 

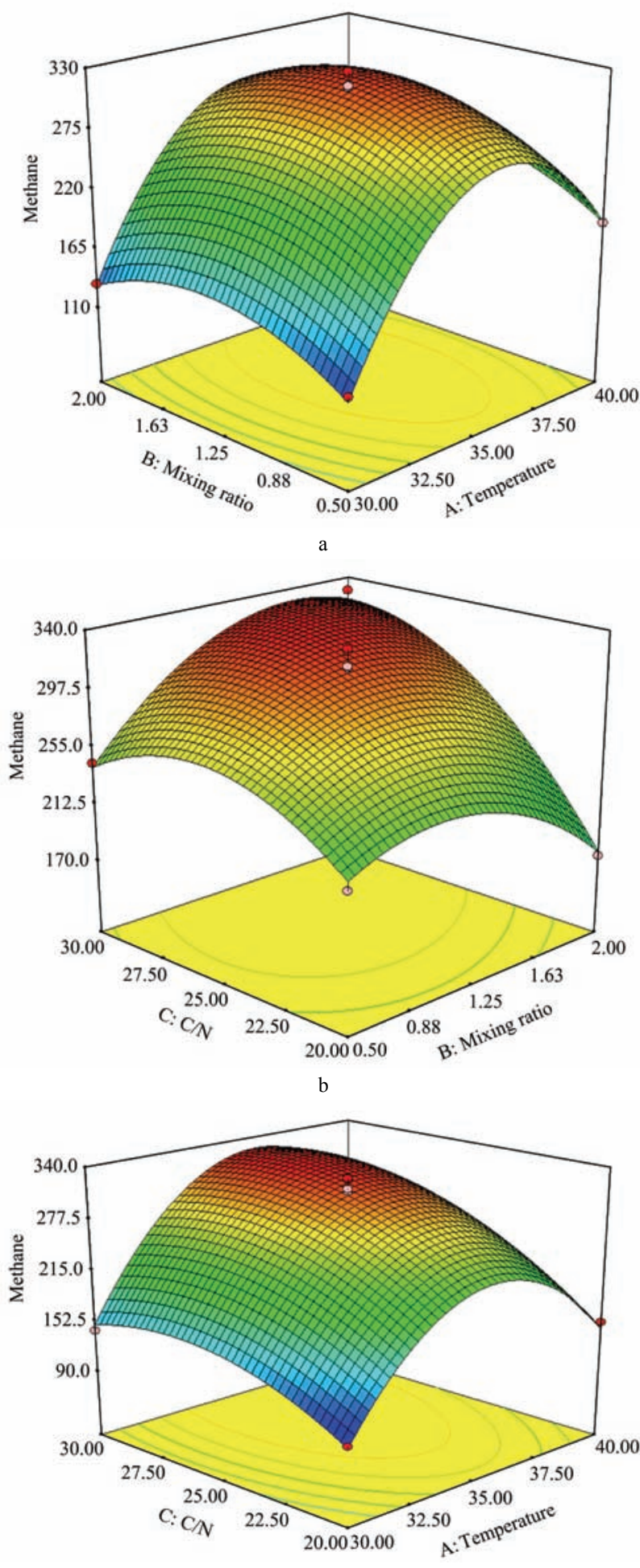

$\mathrm{c}$

Figure 3 Effects of temperature, mixing ratio and $\mathrm{C} / \mathrm{N}$ ratio on biogas production

\subsubsection{Verification tests}

To determine the validity of the predicted values, the experiments were performed at the predicted optimal conditions. For ease of operation, the conditions were adjusted to $36^{\circ} \mathrm{C}$, mixing ratio of 1.6 , and $\mathrm{C} / \mathrm{N}$ ratio of $29 . \mathrm{AD}$ of mixed raw materials was taken under the same experimental conditions with the adjusted optimal parameters. The experimental results yielded a biogas production of $342.2 \mathrm{~mL} / \mathrm{g}$ TS, which was consistent with the result from the modeling of $\mathrm{AD}(338.56 \mathrm{~mL} / \mathrm{g} \mathrm{TS})$. The results showed that the actual biogas production can be well forecasted using the RSM method and the forecasting value of biogas production can also be accurately calculated using this method.

\section{Conclusions}

Pretreatment of SL with $\mathrm{NaOH}$ improved the degradation of lignocellulosic compounds. The content of $\mathrm{LCH}$ in four $\mathrm{NaOH}$ pretreated samples were decreased by $5.79 \%-16.85 \%$ and the cumulative biogas production was increased by $34.54 \%-82.67 \%$ compared with the untreated SL. Co-digestion of SL with livestock manure improved biogas production significantly. The optimization experiment showed a significant interactive effect of temperature, mixing ratio and $\mathrm{C} / \mathrm{N}$ ratio on $\mathrm{AD}$. The RSM results indicated the optimal conditions for biogasification was at temperature of $36.2^{\circ} \mathrm{C}$, mixing ratio of $1.61: 1$ and $\mathrm{C} / \mathrm{N}$ ratio of $29.2: 1$. Therefore, it would be better to pretreat SL in order to improve biodegradability and enhance biogas production.

\section{Acknowledgments}

We acknowledge that this work was financially support by Special Fund for Agroscientific Research in the Public Interest (No.201503135): Study on Technology and Demonstration of Straw High Efficiency and Clear Energy Utilization.

\section{[References]}

[1] Nansubuga I G, Banadda N, Babu M, De Vrieze J, Verstraete W, Rabaey K. Enhancement of biogas potential of primary sludge by co-digestion with cow manure and brewery sludge. Int J Agric \& Biol Eng, 2015; 8(4): 86-94.

[2] Neshat S A, Mohammadi M, Najafpour G D, Lahijani P. Anaerobic co-digestion of animal manures and lignocellulosic residues as a potent approach for sustainable biogas production. Renewable \& Sustainable Energy Reviews, 2017; 79: 308-322.

[3] Hassan M, Umar M, Ding W M, Shi Z D, Zhao S Q. Methane enhancement through co-digestion of chicken manure and oxidative cleaved wheat straw: Stability performance and kinetic modeling perspectives. Energy, 2017; 141: 2314-2320.

[4] Risberg K, Sun L, Levén L, Horn S J, Schnurer A. Biogas production from wheat straw and manure - Impact of pretreatment and process operating parameters. Bioresource Technology, 2013; 149: 232-237.

[5] Wang F, Niu W S, Zhang A D, Yi W M. Enhanced anaerobic digestion of corn stover by thermo-chemical pretreatment. Int J Agric \& Biol Eng, 2015; 8(1): 84-90

[6] Irini A, Wendy S. Assessment of the anaerobic biodegradability of macropollutants. Reviews in Environmental Science and Bio/Technology, 2004; 3: 117-129.

[7] Li K, Liu R H, Cui S F, Yu Q, Ma R J. Anaerobic co-digestion of animal manures with corn stover or apple pulp for enhanced biogas production. Renewable Energy, 2018; 118: 335-342.

[8] Dias T, Fragoso R, Duarte E. Anaerobic co-digestion of dairy cattle manure and pear waste. Bioresource Technology, 2014; 164: 420-423.

[9] Ye J, Li D, Sun Y, Wang G, Yuan Z, Zhen F, et al. Improved biogas production from rice straw by co-digestion with kitchen waste and pig manure. Waste Management, 2013; 33 (12): 2653-2658.

[10] Zhang T, Liu L L, Song Z L, Ren G X, Feng Y Z, Han X H, et al. Biogas production by co-digestion of goat manure with three crop residues. PLoS ONE, 2013; 8(6): e66845.

[11] Mei Z L, Liu X F, Huang X B, Li D, Yan Z Y, Yuan Y X, et al. Anaerobic Mesophilic Codigestion of Rice Straw and Chicken Manure: Effects of Organic Loading Rate on Process Stability and Performance. Applied Biochemistry and Biotechnology, 2016; 179: 846-862.

[12] Chaudhry A S. Rumen degradation in sacco in sheep of wheat straw treated with calcium oxide, sodium hydroxide and sodium hydroxide plus hydrogen peroxide. Animal Feed Science \& Technology, 2000; 83 (3): 313-323.

[13] Feng Y Z, Zhao X L, Guo Y, Yang G H, Xi J C, Ren G X. Changes in the material characteristics of maize straw during the pretreatment process of methanation. Journal of Biomedicine and Biotechnology, 2012; 2012(4): 1-7. Doi: 10.1155/2012/325426.

[14] Paudela S R, Banjara S P, Choi O K, Park K Y, Kim Y M, Lee J W. 
Pretreatment of agricultural biomass for anaerobic digestion: Current state and challenges. Bioresource Technology, 2017; 245: 1194-1205.

[15] Zhu J Y, Wan C X, Li Y B. Enhanced solid-state anaerobic digestion of corn stover by alkaline pretreatment. Bioresource Technology, 2010; 101: 7523-7528.

[16] Sambusiti C, Ficara E, Rollini M, Manzoni M, Malpei F. Sodium hydroxide pretreatment of ensiled sorhum forage and wheat straw to increase methane production. Water Science and Technology, 2012; 66(11): 2447-2452.

[17] APHA, 1998. Standard Methods for the Examination of Water and Wastewater, 20th ed. American Public Health Association, Washington, DC, USA.

[18] Chen H Z, Li Z H. Lignocellulose fractionation. Journal of Cellulose Science and Technology, 2003; 11(4): 31-40.

[19] Zhao P X, Cui F J, Bu L X, Jiang J X. Biogas production from microbial-alkali pretreated corn stover by solid-state anaerobic digestion. Int J Agric \& Biol Eng, 2015; 8(5): 96-104.

[20] Liang Y G, Cheng B J, Si Y B, Cao D J, Li D L, Chen J F. Effect of solid-state $\mathrm{NaOH}$ pretreatment on methane production from thermophilic semi-dry anaerobic digestion of rose stalk. Water Science \& Technology, 2016; 73(12): 2913-2920.

[21] Chen H Z, Liu U Y, Yang X X, Li Z H. New process of maize stalk amination treatment by steam explosion. Biomass Bioenergy, 2005; 28 : 411-417.
[22] Curreli N, Fadda M B, Rescigno A, Rinaldi A C, Soddu Giulia, Sollai F, et al. Mild alkaline/oxidative pretreatment of wheat straw. Process Biochem, 1997; 32: 665-670.

[23] He Y F, Pang Y Z, Liu Y P, Li X J, Wang K S. Physicochemical characterization of rice straw pretreated with sodium hydroxide in the solid state for enhancing biogas production. Energy \& Fuels, 2008; 22(4): 2775-2781.

[24] Pavlostathis S G, Gossett J M. Alkaline treatment of wheat straw for increasing anaerobic biodegradability. Biotechnology \& Bioengineering, 1985; 27: 334-344.

[25] Yuan H R, Li R P, Zhan Y T, Li X J, Liu C M, Meng Y, et al. Anaerobic digestion of ammonia-pretreated corn stover. Biosystems Engineering, 2015; 129: 142-148

[26] Yan Z Y, Song Z L, Li D, Yuan Y X, Liu X F, Zheng T. The effects of initial substrate concentration, $\mathrm{C} / \mathrm{N}$ ratio, and temperature on solid-state anaerobic digestion from composting rice straw. Bioresource Technology, 2015; 177: 266-273.

[27] Verma S. Anaerobic digestion of biodegradable organics in municipal solid wastes (Master thesis). Department of Earth and Environmental Engineering (Henry Krumb School of Mines), Columbia University, USA 2002

[28] Wang M, Li W Z, Li P F, Yan S P, Zhang Y L. An alternative parameter to characterize biogas materials: Available carbon-nitrogen ratio. Waste Management, 2017; 62: 76-83. 